\title{
Online Student Expectations: A Multifaceted, Student-centred Understanding of Online Education
}

\author{
Mel Henry \\ Curtin University, Australia
}

\begin{abstract}
University students are more likely to feel satisfied and persist with their studies if their experiences have met their expectations, and vice versa (Wu, Tsai, Chen, \& Wu, 2006). Understanding what online students expect, therefore, is important to guide how universities might satisfy and retain these students. Research into online student expectations to date, however, has been limited to pre-defined expectations of the academic experience, and extrapolations from traditional higher education. To gain a deeper understanding of what online students expect, the author conducted indepth interviews with 43 commencing online students. Thematic analysis revealed online students' expectations were described by six key themes: Motivation, Ability, Circumstances, Interaction, Curriculum, and Environment. The findings offer an empirical, student-centred, and multifaceted understanding of online student expectations. Opportunities are illuminated to clarify inaccurate expectations, and to design online education to better meet student needs, facilitating enhanced online student satisfaction and retention.
\end{abstract}

Keywords: Student expectations; online education; retention; student satisfaction.

\section{Introduction}

Online education (OE) is a core aspect of modern higher education (HE), with university students increasingly choosing to study online (Australian Government, 2018). OE offerings have grown world-wide, leaving universities to compete for online students in a global HE market (Allen et al., 2016; Universities Australia, 2013). This global online HE market offers students extensive choice in their education, with student satisfaction and perceived value for money vital to attract and retain students (Universities Australia, 2014). Understanding online students' expectations is essential to empower universities to design and deliver education that meets students' needs, facilitating strong outcomes that justify and drive public, institutional and personal investment (Australian Government, 2011). Student expectations of OE, however, remain under-researched (Wieser et al., 2017). OE research and practice often focus on the institution and its teaching, pre-defined constructs, and comparisons to oncampus education, neglecting a more holistic and student-centred understanding of online student expectations (Social Research Centre, 2017).

Recent research has called for institutions to develop a more nuanced understanding of who their online students are, and what they might need (Balloo, 2018; O'Shea et al., 2015; Stone, 2017). Understanding students' expectations and needs enables universities to design programs that meet these needs and empower students to achieve strong outcomes. Students are more likely to feel satisfied and persist with their studies if their experiences are perceived to have met their expectations, and vice versa (Wu et al., 2006). Knowing what students expect, therefore, is an essential first step towards facilitating online student satisfaction and retention. 
Some student expectations may be inferred from promoted OE benefits. OE enables universities to reach those who may be less available for traditional study and offers flexibility through anywhere, anytime access (Serhan, 2010). Students may choose to study online where this flexibility suits their individual needs, availability, location, family and work commitments, and aspirations (Henry et al. 2014). Understanding of what online students might expect, beyond this initial motivation to apply, however, remains limited.

Existing OE literature relies heavily on quantitative data and predefined variables, often inferred from traditional HE, neglecting the online student perspective. Research has focused on assessing specific expectations (e.g., Balloo, 2018; Hassel \& Ridout, 2018), or implied inaccurate expectations based on students' reasons for withdrawing (e.g., Scutter et al., 2011). Studies have also relied largely on quantitative surveys (e.g., Broeckelman-Post \& MacArthur, 2018; Cavanaugh \& Jacquemin, 2015), and on comparing online and on-campus outcomes (e.g., Garratt-Reed et al., 2016). This reliance on predefined constructs, grounded in traditional HE, restricts understanding to known issues and prevents identification of additional online student expectations.

The importance of the total 'Student Experience' (Harvey et al., 1992, cited in Benckendorff et al., 2009) is well recognised in traditional HE. Understanding of online student expectations, however, remain focused on the academic experience (e.g., Garratt-Reed et al., 2016). Few studies have openly examined online student expectations to consider non-academic aspects, such as lifestyle, extracurricular activities, support, and work experience. Instead assumptions of students' broader expectations are often extrapolated from understanding of traditional HE (e.g., Cavanaugh \& Jacquemin, 2015).

With limited student voice and narrow conceptualisation of online student expectations, potentially critical factors may be overlooked. An open, qualitative exploration of online student expectations, as described by students themselves is needed, therefore, if universities are to meet such expectations, and enhance online student satisfaction and retention. To account for the limitations of previous research, the author conducted an in-depth case study investigation into first-year online university student expectations. This study formed part of a larger $\mathrm{PhD}$ investigation into the online student experience, with the present paper aiming to describe what first-year university students' expect of OE.

\section{Methods}

With approval from the University's Human Research Ethics Committee, 43 first-year domestic students at an Australian public university were recruited through the University's online student portal, and via online Course Coordinators. Participants were provided with a detailed information statement and consent form prior to being interviewed, and were entered in a prize draw to win a $\$ 500$ (AUD) gift voucher following participation.

The participant sample approximately mirrored the University's online student population, with 67 per cent of participants identifying as female; 77 per cent enrolled in Bachelor degrees; 58 per cent studying part-time; and 93 per cent mature aged (aged 21 years or older). While several participants had some experience of HE, many were studying online for the first time $(60 \%)$, and described themselves as reasonably proficient with technology (92\%). Participants were enrolled in a range of study fields, including health (53\%), business (30\%), law (7\%), technology (9\%) and humanities (5\%).

In-depth online interviews were conducted through synchronous, text-based chat in Blackboard and Adobe Connect. An interview schedule was developed, with a list of exploratory questions designed to prompt participants to openly discuss all elements of their expectations. The precise wording and order of prompts were adjusted to individual participants, in order to elicit as much information as possible (Liamputtong \& Ezzy, 2005). Participants were prompted to discuss their expectations of OE openly and broadly. System-generated transcripts were then thematically analysed in NVivo. Themes were identified according to their presence across the participant sample, depth of associated discussions, or ascribed importance by participants. The intention was to build a holistic and qualitative description of online student expectations, in which any recurring theme was viewed as valid, regardless of statistical prevalence. A thematic description of the data was then prepared, and a conformability audit conducted to validate the analysis (Braun \& Clarke, 2006; Kleiman, 2004). Consistent with Descriptive Phenomenology, the researcher actively noted and excluded any subjective thoughts arising throughout data collection and analysis, to prevent interpretation bias (Karlsson, 1993; Kleiman, 2004). 


\section{Findings}

Six overarching themes described participants' expectations of OE: Motivation, Ability, Circumstances, Interaction, Curriculum, and Environment. Each theme is discussed below, with pseudonyms used where quotes are provided.

\section{Motivation}

Participants described their intrinsic desire to engage with their learning. They expected concentration would be particularly important. They anticipated struggling to manage distractions and avoid procrastination in the absence of seeing others studying or attending scheduled classes. Participants expected they might need to more actively focus their attention on study than they would in traditional HE. As Teresa described, “...If I were to study on campus, I'll feel the pressure when I see everyone else studying. But when I'm studying at home, I don't get the pressure and I always tell myself that I'll start studying tomorrow."

Participants expressed strong commitment to their learning and associated career aspirations. Eliza, for instance, described, "I thought long and hard before commiting [sic] to [my studies] ... its [sic] what I want to do and I tend to not give up easily once I've made up my mind." Participants anticipated this determination might wane, however, where activities were less interesting or directly relevant.

Participants were confident in their capacity to succeed. They were mindful of weaknesses, nonetheless, planning to capitalise on strengths and overcome weaknesses as they progressed. Kevin, for instance, described having considered his capabilities in preparation for his studies noting, "I think the good thing is I have identified the weaknesses and stresses I will have with my studies and therefore can work on them."

Participants described their enjoyment of learning, and interest in course topics. They were excited, expecting to enjoy course content and the challenge of learning new things. Carolyn, for instance, explained, "I have a very keen interest in this topic, so because of that I think I will really enjoy the whole process."

Participants expected to attain valuable rewards through learning new concepts, developing capabilities and achieving formal qualifications. They hoped their studies would position them as role models and enable them to contribute to their community. Participants expected to grow personally, challenging themselves and proving they could accomplish significant feats. Gabriel, for instance, described the anticipated rewards of new knowledge and perspectives adding, "It will allow me to 'think outside the square', learn different point of views, increase my knowledge and understanding."

\section{Ability}

Participants discussed their expected competence associated with university and OE. They anticipated strong academic skills would be important, including proficiency in academic language and critical thinking. Less academic and technically experienced students expressed concerns they may be insufficiently skilled, and some anticipated struggling with mathematics. Participants expected a substantial learning curve initially, yet anticipated this would lessen as they progressed. Those who had used computers in their work and personal lives, worked in related fields, or had recently studied, on the other hand, expected this experience would be advantageous. Katie, for instance, described, “...hoping life experience and previous study experience will be a bonus."

Participants were initially unsure and apprehensive about the time required for their studies. They acknowledged that limited availability or poor time management may cause stress, and would affect their progress and performance. Samiyah, for instance, expected she would need to plan her workload well, adding, "I hope it won't be full on and I can't keep up with it ... think I will go ok as long as I plan myself well."

Participants expected to direct, manage and stimulate their own learning. Some were enticed by this opportunity to learn when and how they chose. Others worried they might become lazy or disorganised in the absence of imposed participation requirements or proactive instruction. Julie, for instance, expected, "The attendance is up to me personally as you can access it $24 / 7$... Accessing online lectures in my own time ... basically its [sic] up to me." 


\section{Circumstances}

Participants discussed their lifestyle, availability and energy for study. Upon commencing, participants' responsibilities were numerous, with study not necessarily their top priority. Many were working full-time, and/or caring for young children, or family with disability. They expressed concern for how they would manage these commitments alongside their studies. Participants expected juggling multiple priorities would be challenging and may rely on good time management, but this balance would be central to their wellbeing. Catherine, for instance, described her concerns about balancing simultaneous priorities adding, "I worry that I won't be able to do everything well, being a good mum/ wife/ employee. I worry that I will be extremely stressed and not have time to exercise."

Participants saw $\mathrm{OE}$ as a specific means to learn alongside multiple priorities. They planned to manage their studies around employment and family responsibilities. Marcus, for instance, described having chosen to study online to accommodate other commitments, adding "... I can fit things round my work and life commitments - and golf!"

Participants expected to be supported by family, friends, employers and their university. They hoped to receive help with family responsibilities; and to access assistance from others familiar with their field of study, HE, technology, or OE. Participants hoped employers would afford them flexibility in work hours and leave, access to workplace resources, and/or contribute to course costs. They were aware university services may also be available, but unsure what might be accessible to online students, or did not see such services as applicable. Largely, participants expected to manage without university support, as described by Andrea who said, "I know there are people I can talk to at [the case university] if I need to ... I feel I have enough people around me to help me get through."

Participants expressed concerns about their health and/or disability, and the potential impact on their studies. Some experienced chronic health conditions or disability, and anticipated these might disrupt participation in their online course. Martin, for instance, explained, "The health problems can stop me dead in my tracks."

Participants primarily expected to study at home, with some study at work, in a library, or university campus. Participants also anticipated studying while in transit; listening to lecture podcasts on their phone or in the car, and working from a laptop at various locations. As Samantha noted, "Everything on the laptop ... Don't think I will go anywhere where won't be able to take studies with me."

\section{Interaction}

Participants discussed formal and informal opportunities to interact with others in their course, and with course content. They expected instructors would provide timely guidance, feedback and support; helping students identify what they should be doing, when and why. Holly, for instance, expected "Fast replies to questions ... email support, like questionslanswer and advice."

Participants expected to engage in regular online peer discussions and desired informal connections. They hoped to be supported academically and socially by their peers, helping to develop and clarify their understanding, and making them feel part of the university community. Delores, for instance, described her anticipation of peer connection and support saying, "[I] will be able to interact with students for moral support ... share experiences and to bounce ideas off."

Some participants anticipated learning independently. They expected little contact with other students, and for instruction to primarily consist of generic announcements and assignment feedback, unless they actively sought further clarification. These participants worried they may be disadvantaged by a lack of interaction, leaving them isolated or lost. Some described a preference for on-campus education because of this interaction, though their circumstances prevented it. Stephanie, for instance, expected limited interaction in OE adding, "Studying online isn't my ideal thing. I would like to have studied oncampus [sic] and where I could network with others."

A small number of participants expected peer interaction might distract from their studies. These students felt OE offered a valuable opportunity to learn independently, enabling them to focus purely on course content and assessment. One such student, Gabriel, explained he was "Not really looking for any social interaction more just want to focus on the course." 
Participants expected to primarily engage with their studies through readings and slide presentations. They hoped to also access audio or video recordings and interactive online classes. Participants anticipated a substantial amount of reading, potentially more than on-campus programs, with much of the course content delivered in this way. Eva noted, "I think it will mean more reading and more looking a [sic] other resources than ... attending lectures [on campus]."

\section{Curriculum}

Participants discussed expected course flexibility, challenge and relevance. They anticipated the course structure to be flexible, allowing them to participate at their own pace, convenience and discretion. Laverne said, "I don't have to attend anything really ... Its [sic] up to me what I do and don't do I guess, but I am aware of the 'uni recommendations'."

Participants anticipated their course would be difficult. They expected to struggle with mathematics; and social science students expected their attitudes toward particular issues might be challenged. Participants were positive about these difficulties, however, noting challenges as important for completion and success to be meaningful. Andrea, for instance, described her anticipation of being challenged adding, "I know its [sic] going to be difficult. I am expecting it to challenge my own beliefs and ideas ... a challenge but one I'm looking forward to."

Participants expected their course would be relevant and applicable to the real world. They hoped to gain valuable knowledge that would prepare them for subsequent semesters and future employment. Carolyn, for instance, said, "Hopefully will allow me to gain the knowledge to further my career prospects."

\section{Environment}

Participants described their expectations of the online learning environment. They expected the course to run in a similar manner to on-campus education, with materials and communication simply delivered electronically, and activities completed at a distance, rather than through attendance at classes on campus. As Sean described, "Basically I have all the stuff to learn, without the tutor/lecutrer [sic] physically being there ... I would 'assume' like any other person doing this course 'internally', I wouldn't percieve [sic] a difference."

Participants expected to rely heavily on dependable and accessible technology. They were excited about using technology for learning. Some recognised they may not yet be fully proficient with technology, nonetheless, and anticipated technical difficulties might occur. Participants expressed concerns about potential hardware breakdowns, software errors, connection difficulties and system failures, and the impact on their studies. Delores, for instance, said, "My concern is the system going down, or even for system back up ... online student highly depend on the system to do their work ... if essays were due I would hope that submission wouldn't be classified as late."

\section{Discussion}

The findings offer a detailed and multifaceted description of first-year university students' expectations of OE. Participants' expectations were complex and multidimensional, relating to both their personal characteristics and situation, and to their institution. Students were mindful of their own motivation, ability and circumstances; and anticipated conditions associated with institutional interaction, curricula and learning environments. These findings offer empirical, qualitative evidence for what students expect of OE, extending understanding of who online students are, and what they may need to succeed.

The findings suggest online students recognise the role they play in their experience of OE, mindful of their own motivation, ability and circumstances as they embark on their first year of study. As in traditional HE, commencing online students are excited about their studies and confident in their capability (Hassel \& Ridout, 2018). They recognise, nevertheless, that it takes more than mere interest in a topic for them to succeed. Students anticipate the value of persistent concentration and commitment, strong academic and technical skills, content familiarity, organisation and self-regulation (Hassel \& Ridout, 2018). Online students may be unsure of the required time commitments, and concerned about their capacity to manage their workload amidst work and family responsibilities (Stone \& O'Shea, 2019; Su \& Waugh, 2018), or health concerns. They expect to take some responsibility for managing their learning and appreciate a need to be proactive. Students may be unsure of university services available to online students, or may not feel these services are applicable (Hanover Research, 2012). Though they anticipate 
some support from family, friends, employers and their university, online students expect to cope on their own. They expect to engage with learning activities in varied locations, furthermore, dependent on individual preferences, availability and surroundings.

Alongside students' personal situation and attributes, they hold expectations of their institution, with regard to interaction, curriculum and the learning environment. From their institution, online students expect meaningful interaction, with guidance, feedback and support from instructors, dynamic course materials, and quality connections with peers for social and academic support (Stone \& O'Shea, 2019). They anticipate their curriculum being flexible, challenging and relevant (Stone et al., 2016); and welcome potential challenges. Students expect a quality online learning environment, commensurate with the assumed oncampus experience (Stone \& O'Shea, 2019). They foresee a heavy reliance on accessible and dependable technology, nonetheless, anticipating initial problems navigating online systems, and some technical difficulties.

Together, these findings present a rich description of the many facets to first-year university students' expectations of OE. Recognising their own contribution, online students commence their studies focused on their strengths and aspirations, yet mindful of potential challenges associated with maintaining their motivation, developing their abilities, and facilitating circumstances conducive to study. In addition, students expect their university to support and enable their learning through meaningful interaction, a relevant, flexible and challenging curriculum, and a reliable learning environment. These expectations extend well beyond academic experiences and reflect awareness of potential challenges and personal responsibilities, adding to prior understanding. Participants did not expect to be passive learners, or for OE to be easier than traditional HE (DiRienzo \& Lilly, 2014). Rather, online students are cognisant of potential challenges and see the opportunity to overcome such difficulties as a measure of course value. The negative expectations described by participants, furthermore, reinforce a distinction between desires and expectations, and the importance of recognising this difference in the literature (Balloo, 2018).

The range of identified themes supports broad conceptualisation of online student expectations, incorporating both institutional and learner factors. The circumstances in which students engage with their studies, and the motivation and abilities they bring with them, provide an important additional lens through which online student outcomes should be interpreted and enhanced (Stone \& O'Shea, 2019). Providing OE that meets (or manages) online students' expectations, and subsequently facilitates student satisfaction and retention (Wieser et al., 2017), therefore, requires additional consideration of these learner themes.

The findings support application of current theory surrounding learning, retention and student satisfaction to OE. Students' expectations of their motivation, ability and circumstances suggest a learner-centred, sociocultural context for the student experience. Supplementing this learner context, identified institutional themes of interaction, curriculum and environment describe students' expectations of their academic experience. These six themes align well with the principles of Constructivist Learning Theory (CLT; Lesgold, 2004). CLT posits that deep learning requires active, learner-centred knowledge construction, informed by previous knowledge, and influenced by the learner's sociocultural context and experiences (Lesgold, 2004; Merriam \& Bierema, 2014). Students' expectations of OE, therefore, appear consistent with experiences conducive to strong learning outcomes (Merriam \& Bierema, 2014).

Identified themes also align with understanding of student retention and satisfaction in traditional and distance HE. Kember's Longitudinal-process Model of Drop-out from Distance Education (1989), for instance, proposes that students' characteristics (individual, family/home, work and educational) inform their goal commitment, which subsequently informs their academic, social and work environments therefore influencing their academic, social and work integration. Students' academic, social and work integration then feeds into students' cost/benefit analysis, informing decisions to withdraw, or continue/complete their course. Identified learner themes (motivation, ability and circumstances) align to Kember's student characteristics and goal commitment components, while institutional themes (interaction, curriculum and environment) reflect the academic environment, with integration of these learner and institutional contexts having the potential to inform students' cost-benefit analysis of persisting. Efforts to meet or clarify online student expectations in these areas, moreover, may help to facilitate student satisfaction and further increase retention (Wu et al., 2006). Consideration to the learner and institutional themes identified in the present research, therefore, may also support enhanced online student satisfaction and retention.

Opportunities to enhance online student outcomes are illuminated through these findings, offering a window into what students may seek from OE. This information may be especially helpful in tailoring OE promotion to tap into potential desires and decision-making around online course selection, while preparing students for a positive online student experience. Identified 
learner characteristics offer a range of potential selection criteria and opportunities for meaningful course advice. Considering students' expectations, aspirations and availability, and assessing prior knowledge and experience, may help place students into the most appropriate study pathways. Challenges anticipated by some participants, furthermore, highlight the importance of normalised and accessible online student support, particularly with regards to academic skills, computer literacy/technical trouble-shooting, and time management; which may facilitate a more equitable and manageable first-year transition.

Reviewing online course design, instruction and support in light of identified student expectations may also uncover potentially inaccurate expectations. Expectations can be clarified in promotional materials, and/or programs adapted to better match students' expectations. In particular, prospective online students may benefit from clear information about expected time commitments, levels of interaction, extent of participation flexibility, technical requirements, and requisite skillsets. This information may assist online students to effectively prepare and make informed decisions about their studies.

Universities also have some responsibility to satisfy student expectations by facilitating experiences that meet learners' needs (Universities Australia, 2014). Institutions should examine their practices, standards and quality assurance mechanisms in relation to interaction, curriculum, and environment, in particular, to ensure these align with students' expectations of OE, or else clarify and explain why students' expectations may not be satisfied. Universities should consider the circumstances in which online students are placed, furthermore, and ensure appropriate flexibility and support is available to enable these students to participate and succeed in their studies (Stone \& O'Shea, 2019).

\section{Conclusion}

The present research offers a much needed empirical, student-centred and multifaceted understanding of online students' expectations. It responds to an identified need to understand what online students expect (O'Shea et al., 2015; Wieser et al., 2017), and contributes to the student perspective of OE, which has been neglected to date. The findings add to an understanding of the total online student experience, and inform universities of how they might adapt to meet the growing demand for OE. Understanding what online students expect will enable universities to enhance student satisfaction and retention, positioning them more competitively on a global stage. Further research is needed to validate these findings for other online first-year student populations, including a larger scale quantitative study to assess the prevalence of expectations described herein. Further investigation of how identified expectations relate to subsequent student experiences, and how these contribute to online student outcomes, is also an essential supplement to these findings, and will be the subject of further papers.

\section{References}

Allen, I. E., Seaman, J., Poulin, R., \& Taylor Straut, T. T. (2016). Online report card: Tracking online education in the United States. http://webmedia.jcu.edu/institutionaleffectiveness/files/2016/06/onlinereportcard.pdf

Australian Government. (2011). Higher education standards framework. Department of Industry, Innovation, Science, Research and Tertiary Education. https://www.legislation.gov.au/Details/F2012100003/Html/Text\# Toc311791709

Australian Government. (2018). Selected higher education statistics - 2018 Student data. Department of Education. https://www.education.gov.au/selected-higher-education-statistics-2018-student-data

Balloo, K. (2018). In-depth profiles of the expectations of undergraduate students commencing university: A Q methodological analysis. Studies in Higher Education, 43(12), 2251-2262. https://doi.org/10.1080/03075079.2017.1320373

Benckendorff, P., Ruhanen, L., \& Scott, N. (2009). Deconstructing the student experience: A conceptual framework. Journal of Hospitality and Tourism Management, 16, 84-93. https://doi.org/10.1375/jhtm.16.1.84

Braun, V., \& Clarke, V. (2006). Using thematic analysis in psychology. Qualitative Research in Psychology, 3(2), $77-101$. https://doi.org/10.1191/1478088706qp063oa

Broeckelman-Post, M. A., \& MacArthur, B. L. (2018). Are we violating student expectations? Availability, workload, class time use, and technology policies in undergraduate courses. Journalism and Mass Communication Educator, 73(4), 439453. https://doi.org/10.1177/10776958I7736687

Cavanaugh, J. K., \& Jacquemin, S. J. (2015). A large scale comparison of grade based student learning outcomes in online vs. face-to-face courses. Journal of Asynchronous Learning Networks, 19(2). https://doi.org/10.24059/olj.v19i2.454

DiRienzo, C., \& Lilly, G. (2014). Online versus face-to-face: Does delivery method matter for undergraduate business school learning? Business Education and Accreditation, 6(1), 1-11. https://doi.org/10.1080/08832323.2015.1087371 
Garratt-Reed, D., Roberts, L. D., \& Heritage, B. (2016). Grades, student satisfaction and retention in online and face-to-face introductory psychology units: A test of Equivalency Theory. Frontiers in Psychology, 7, 1-10. https://doi.org/10.3389/fpsyg.2016.00673

Hanover Research. (2012). Student services for online learning: Finding the student's perspective. Hanover Research.

Hassel, S., \& Ridout, N. (2018). An investigation of first-year students' and lecturers' expectations of university education. Frontiers in Psychology, 8, 1-13. https://doi.org/10.3389/fpsyg.2017.02218

Henry, M., Pooley, J. A., \& Omari, M. (2014). Student motivations for studying online: A qualitative study. Paper presented at the Transformative, innovative and engaging: The 23rd Annual Teaching Learning Forum, Perth: The University of Western Australia.

Karlsson, C. (1993). Psychological qualitative research from a phenomenological perspective. Almqvist \& Wiksell International.

Kember, D. (1989). A longitudinal-process model of drop-out from distance education. Journal of Higher Education, 60(3), 278-301. https://doi.org/10.2307/1982251

Kleiman, S. (2004). Phenomenology: To wonder and search for meanings. Nurse Researcher, 11(4), 7-19. https://doi.org/10.7748/nr2004.07.11.4.7.c6211

Lesgold, A. (2004). Contextual requirements for constructivist learning. International Journal of Educational Research, 41 , 495-502. https://doi.org/10.1016/j.ijer.2005.08.014

Liamputtong, P., \& Ezzy, D. (2005). Qualitative research methods (2nd ed.). Oxford University Press.

Merriam, S., \& Bierema, L. (2014). Adult learning: Linking theory and practice: John Wiley \& Sons, Incorporated.

O'Shea, S., Stone, C., \& Delahunty, J. (2015). "I 'feel' like I am at university even though I am online." Exploring how students narrate their engagement with higher education institutions in an online learning environment. Distance Education, 36(1), 41-58. https://doi.org/10.1080/01587919.2015.1019970

Scutter, S., Palmer, E., Luzeckyj, A., Burke da Silva, K., \& Brinkworth, R. (2011). What do commencing undergraduate students expect from first year university? The International Journal of the First Year in Higher Education, 2(1), 8-20. https://doi.org/10.5204/intjfyhe.v2i1.54

Serhan, D. (2010). Online learning: Through their eyes. International Journal of Instructional Media, 37(1), 19-24.

Social Research Centre. (2017). Quality Indicators for Learning and Teaching (QILT). https://www.qilt.edu.au

Stone, C. (2017). Opportunity through online learning: Improving student access, participation and success in higher education. National Centre for Student Equity in Higher Education. https://www.ncsehe.edu.au/publications/opportunityonline-learning-improving-student-access-participation-success-higher-education/

Stone, C., \& O'Shea, S. (2019). My children... think it's cool that Mum is a uni student: Women with caring responsibilities studying online. Australasian Journal of Educational Technology, 35(6), 97-110. https://doi.org/10.14742/ajet.5504

Stone, C., O'Shea, S., May, J., Delahunty, J., \& Partington, Z. (2016). Opportunity through online learning: Experiences of first-in-family students in online open-entry higher education. Australian Journal of Adult Learning, 56(2), 146-169.

Su, J., \& Waugh, M. L. (2018). Online student persistence or attrition: Observations related to expectations, preferences, and outcomes. Journal of Interactive Online Learning, 16(1), 63-79.

Universities Australia. (2013). An agenda for Australian higher education 2013-2016: A smarter Australia. http://www.universitiesaustralia.edu.au

Universities Australia. (2014). The student experience. http://www.universitiesaustralia.edu.au/uni-participationquality/students/The-Student-Experience\#.WH7M7FV9671

Wieser, D., Seeler, J. M., Sixl-Daniell, K., \& Zehrer, A. (2017). Online students' expectations differ: The advantage of assessing students' expectations in online education. Paper presented at the 3rd International Conference on Higher Education Advances, HEAd'17, Univerrsitat Politecnica de Valencia, Valencia.

Wu, J., Tsai, R. J., Chen, C. C., \& Wu, Y. (2006). An integrative model to predict the continuance use of electronic learning systems: Hints for teaching. International Journal on E-Learning, 5(2), 287-302.

Please cite this article as:

Henry, M. (2020). Online student expectations: A multifaceted, student-centred understanding of online education. Student Success, 11(2), 91-98. https://doi.org/10.5204/ssj.1678

This article has been peer reviewed and accepted for publication in Student Success. Please see the Editorial Policies under the 'About' section of the Journal website for further information

Except where otherwise noted, content in this journal is licensed under a Creative Commons Attribution 4.0 International Licence. As an open access journal, articles are free to use with proper attribution. ISSN: 2205-0795 